\title{
Phenotypic characteristics and tendency to apoptosis of peripheral blood mononuclear cells from HIV+ long term non progressors
}

\author{
Claudio Franceschi ${ }^{1,2}$, Maria Grazia Franceschini ${ }^{1}$, \\ Antonio Boschini ${ }^{3}$, Tommaso Trenti ${ }^{4}$, Cira Nuzzo ${ }^{4}$, \\ Gastone Castellani ${ }^{3}$, Camillo Smacchia ${ }^{3}$, Bruno De Rienzo ${ }^{5}$, \\ Roberto Roncaglia $^{6}$, Marinella Portolani ${ }^{7,8}$, \\ Paola Pietrosemoli ${ }^{8}$, Marisa Meacci ${ }^{8}$, Monica Pecorari ${ }^{8}$, \\ Anna Sabbatini ${ }^{8}$, Walter Malorni ${ }^{9}$ and Andrea Cossarizza ${ }^{1,10}$ \\ ${ }^{1}$ Department of Biomedical Sciences, Section of General Pathology, University \\ of Modena, via Campi 287, 41100 Modena, Italy; \\ 2 INRCA, Department of Gerontological Sciences, Ancona; \\ ${ }^{3}$ Comunità di San Patrignano, Rimini; \\ ${ }^{4}$ Department of Internal Medicine, Section of Toxicology, University of \\ Modena; \\ 5 Department of Internal Medicine, Section of Infectious Diseases, University of \\ Modena; \\ ${ }^{6}$ Transfusional Service, USL 16, Modena; \\ 7 Section of Hygiene, Department of Biomedical Sciences, University of \\ Modena; \\ ${ }^{8}$ Virology Service, USL 16, Modena; \\ ${ }^{9}$ Department of Ultrastructures, Istituto Superiore di Sanità, Roma. \\ 10 corresponding author: A. Cossarizza, Department of Biomedical Sciences, via \\ Campi 287, 41100 Modena, Italy. tel: +39 59 428613; fax: +39 59 428623; \\ E-mail: cossariz@unimo.it
}

Received 6.12.96; revised 20.5.97; accepted 14.7.97 Edited by M.L. Gougeon

\begin{abstract}
The aim of this study was to analyze (i) phenotype, (ii) in vitro spontaneous and induced apoptosis, (iii) glutathione (GSH) intracellular content and (iv) inhibitors of apoptosis of potential therapeutical use in peripheral blood mononuclear cells (PBMC) from HIV+ long term non progressors (LTNP), in comparison with progressors $(\mathrm{HIV}+\mathrm{P})$ and seronegative controls (HIV-). Three groups of subjects were studied: 15 HIV+P (patients losing $>150$ CD4+/year), 9 LTNP (subjects infected by HIV for at least 7 years without clinical and immunological signs of progression, with a mean of 898 $\mathrm{CD} 4+/ \mu \mathrm{L}$ ) and $18 \mathrm{HIV}-$. All subjects were living in a large community for former drug addicts, and were matched for age and sex.

We used flow cytometry for analyzing PBMC phenotype and apoptosis; high performance liquid chromatography for measuring intracellular GSH content. PBMC phenotype of LTNP shared characteristics with those of both HIV - and HIV+P. Indeed, LTNP showed a normal number CD4+ cells (an inclusion criteria), butsignificantly increased numbers of CD8+ lymphocytes, activated T cells, CD19+, CD5+ B lymphocytes and CD57+ cells, as well as a decrease in CD19+, CD5 - B lymphocytes and CD16+ cells. In LTNP, spontaneous apoptosis was similar to that of HIV - and significantly lower
\end{abstract}

than that of HIV+P. Adding interleukin-2 (IL-2) or nicotinamide (NAM) significantly decreased spontaneous apoptosis in LTNP and HIV+P. Pokeweed mitogen-induced apoptosis was also similar in LTNP and HIV - , but significantly lower than that of HIV+P. In HIV+P, butalso in LTNP, spontaneous apoptosis was inversely correlated to the absolute number and percentage of CD4+ cells and directly correlated to the number and percentage ofactivated Tcellspresentin peripheralblood.GSH intracellular content was greatly decreased in PBMC from $\mathrm{HIV}+\mathrm{P}$ and slightly, but significantly, reduced in LTNP. Adding 2-deoxy-D-ribose, an agent provoking apoptosis through GSH depletion, to quiescent PBMC resulted in similar levels of massive cell death in the three groups. This phenomenon was equally prevented in the three groups by $\mathrm{N}$-acetyl-cysteine but not by IL-2.

A complex immunological situation seems to occur in LTNP. Indeed, PBMC from LTNP are characterized by a normal in vitro tendency toundergoapoptosis despitethepresenceofastrong activation of their immune system, unexpectedly similar to that of HIV+P. Our data suggest that NAM and IL-2 are possible candidates for reducing spontaneous apoptosis in HIV infection.

Keywords: HIV; AIDS; long term non progressors; glutathione; apoptosis

Abbreviations: LTNP, long term non progressors; HIV+P, seropositive progressor; PBMC, peripheral blood mononuclear cells; HIV, human immunodeficiency virus-1; D-RIB, 2-deoxyD-ribose; GSH, glutathione; IL-2, interleukin-2; NAM, nicotinamide

\section{Introduction}

The gradual depletion of peripheral blood $\mathrm{T}$ lymphocytes, either CD4+ or CD8+, during the progression of human immunodeficiency virus (HIV) infection, may be due, at least in part, to apoptosis (Ameisen and Capron, 1991; LaurentCrawford et al, 1991; Terai et al, 1991). The molecular and cellular mechanisms of this phenomenon are still poorly understood, even if several data suggest that apoptosis is linked to several events typical of HIV infection, including cell activation, cytopathic effect of HIV, syncytia formation and can be triggered-directly or indirectly (production of cytokines) by HIV gene products such as gp120 and gp41, tat protein, or by antigenic stimulations (Groux et al, 1992; Finkel and Banda, 1994; Ameisen et al, 1995; Li et al, 1995; Pantaleo and Fauci, 1995a; Pantaleo and Fauci, 1995b). In particular, it has been reported that, when cultured in vitro, peripheral lymphocytes from HIV+ subjects in different stages of the 
infection undergo apoptosis either spontaneously or following stimulation with polyclonal mitogens or superantigens. Such a phenomenon, which is present at a very low level also in cells from normal subjects, is dramatic during acute HIV infection (Cossarizza et al, 1997), and increases in peripheral blood mononuclear cells (PBMC) from HIV-infected patients with progression of the disease (Gougeon, 1995; Gougeon et al, 1996). However, the relationship(s) between in vitro tendency to undergo apoptosis and the phenomena responsible in vivo for the progressive deterioration of the immune system are far from being clear (Baltimore, 1995a; Pantaleo and Fauci, 1995a). In order to gain further insight on this important topic, we thought worthwhile to study a group of 'long term non progessors' (LTNP), i.e. HIV+ patients whose main feature is the lack of clinical signs of disease progression and of the characteristic decrease of peripheral CD4+, despite being infected by HIV since several years (Levy, 1993; Sheppard et al, 1993). Recent data on LTNP indicate that they have low levels of HIV-1 in the presence of strong virus-specific immune responses, combined with some degree of viral attenuation (Cao et al, 1995). Similar observations concerning low plasma levels of HIV-1 RNA and viral burden in PBMC from LTNP have been reported by Pantaleo et al, who also showed that lymph-node architecture and immune function appear to remain intact in these subjects (Pantaleo et al, 1995).

Accordingly, the main aims of this study were the following: (i) to ascertain whether PBMC from LTNP have a different tendency to undergo apoptosis either spontaneously or after treatment with a mitogen (pokeweed mitogen, PWM), or with anti-CD95 monoclonal antibodies, in comparison with cells from subjects who show signs of progression of the infection $(\mathrm{HIV}+\mathrm{P})$ and from seronegative controls; (ii) to identify the phenotype of apoptotic cells, in order to see whether in LTNP different lymphocyte subsets have a different propensity to cell death; (iii) to ascertain whether spontaneous or induced apoptosis can be modulated by agents such as growth factors (interleukin-2, IL-2), molecules able to inhibit poly(ADPribosyl)polymerase (nicotinamide, NAM; 3-aminobenzamide, 3-ABA), or to increase intracellular reduced glutathione (GSH) content (N-acetyl-L-cysteine, NAC) or energy charge (L-acetyl-carnitine, LAC).

Moreover, we addressed another problem regarding the intracellular glutathione content in PBMC from LTNP. The critical role of intracellular thiols, and in particular of glutathione, for several immune phenomena (reviewed by Dröge et al, 1994) and for the survival of HIV-infected cells (Eck et al, 1991, 1992; Staal et al, 1992a) as well as for the survival of HIV+ patients (Herzenberg et al, 1997) has been reported. Thus, we thought it worthwhile to measure this thiol, and to study the sensitivity of PBMC from LTNP, as well as HIV - and HIV+P, to 2-deoxy-D-ribose (D-RIB), a simple sugar which induces apoptosis and a marked decrease in GSH intracellular content in human PBMC, whose action can be completely inhibited by NAC (Barbieri et al, 1994).

\section{Results}

Table 1 shows the main phenotypic characteristics of lymphocytes from the patients and controls we have studied. LTNP present a significant increase in CD8+ cells, which are likely to be mainly responsible for the altered CD4/CD8 ratio. Moreover, most CD8+ T cells, either from LTNP or HIV+P, also expressed CD57 and CD3 molecule (not shown), indicating that these cells were cytotoxic T lymphocytes (Lanier and Loken, 1984). A relevant percentage of $T$ cells from LTNP, similar to that of HIV+P, expressed markers of activation such as HLA-DR molecules, and the main activated T cells were CD8+ (not shown). The total number of B cells was similar in the three groups, even if we observed an increase in the subset of CD5+ $B$ cells either in LTNP or in HIV+P, and a decrease in CD5 - B cells. Cells with markers related to natural killer (NK) activity had a different behaviour. Indeed, CD16+ and CD56+ cells, i.e. those with higher cytotoxic activity, were overall decreased in LTNP as well as in HIV+P, while CD57+ cells (among which there was a consistent amount of CD8+, CD16 - cells) were significantly increased in all HIV infected subjects.

Table 1 Absolute number and percentages of peripheral blood leukocytes, monocytes, lymphocytes and lymphocyte subpopulations in control seronegative subjects (HIV - ), seropositive progressors $(\mathrm{HIV}+\mathrm{P})$ and long term non progressors (LTNP)

\begin{tabular}{|c|c|c|c|}
\hline & HIV - & HIV+P & LTNP \\
\hline Subjects (N.) & 18 & 15 & 9 \\
\hline Age (years) & $29.9 \pm 1.4$ & $28.1 \pm 1.1$ & $32.0 \pm 1.7$ \\
\hline Leukocytes/ $\mu$ l & $7,304 \pm 316$ & $5,671 \pm 391^{\star *}$ & $6,422 \pm 401$ \\
\hline Monocytes \% & $6.7 \pm 0.5$ & $6.6 \pm 0.6$ & $6.0 \pm 0.7$ \\
\hline monocytes $/ \mu \mathrm{l}$ & $495 \pm 44$ & $376 \pm 45$ & $398 \pm 61$ \\
\hline Lymphocytes \% & $35.8 \pm 1.7$ & $36.9 \pm 2.6$ & $44.2 \pm 2.8^{\star}$ \\
\hline lymphocytes/ $\mu \mathrm{L}$ & $2,584 \pm 116$ & $2,089 \pm 237$ & $2,785 \pm 122^{\circ}$ \\
\hline CD3 \% & $75.2 \pm 1.5$ & $78.7 \pm 2.6$ & $80.3 \pm 3.0^{*}$ \\
\hline $\mathrm{CD} 3 / \mu \mathrm{L}$ & $1,937 \pm 95$ & $1,675 \pm 225$ & $2,285 \pm 153$ \\
\hline CD4 \% & $40.2 \pm 1.2$ & $18.7 \pm 2.5^{\star \star}$ & $32.6 \pm 2.6^{\star \star \circ \circ}$ \\
\hline $\mathrm{CD} 4 / \mu \mathrm{L}$ & $1.030 \pm 50$ & $404 \pm 76^{\star \star}$ & $898 \pm 67^{\circ}$ \\
\hline CD8 \% & $33.6 \pm 1.6$ & $59.1 \pm 3.2^{\star \star}$ & $50.1 \pm 3.5^{\star *}$ \\
\hline $\mathrm{CD} 8 / \mu \mathrm{L}$ & $870 \pm 67$ & $1,248 \pm 177^{*}$ & $1,401 \pm 130^{\star *}$ \\
\hline CD4/CD8 ratio & $1.27 \pm 0.10$ & $0.37 \pm 0.05^{\star \star}$ & $0.69 \pm 0.09^{\star * \circ \circ}$ \\
\hline Act. T cells $\%$ & $9.2 \pm 0.9$ & $37.1 \pm 3.5^{\star \star}$ & $30.4 \pm 4.8^{\star \star}$ \\
\hline act. $\mathrm{T}$ cells $/ \mu \mathrm{L}$ & $241 \pm 28$ & $814 \pm 178^{\star \star}$ & $863 \pm 150^{\star *}$ \\
\hline Total CD19+ \% & $13.7 \pm 1.3$ & $13.1 \pm 1.5$ & $13.7 \pm 2.6$ \\
\hline total CD19+/ $/ \mu \mathrm{L}$ & $359 \pm 39$ & $250 \pm 27^{*}$ & $376 \pm 64^{\circ}$ \\
\hline CD19+, CD5 - \% & $10.4 \pm 1.0$ & $6.8 \pm 0.7^{*}$ & $6.8 \pm 1.3^{*}$ \\
\hline CD19+, CD5 $-/ \mu \mathrm{L}$ & $265 \pm 24$ & $139 \pm 21^{\star *}$ & $190 \pm 47$ \\
\hline CD19+, CD5+ \% & $3.4 \pm 0.7$ & $6.3 \pm 1.2^{*}$ & $6.9 \pm 1.4^{*}$ \\
\hline $\mathrm{CD} 19, \mathrm{CD} 5+/ \mu \mathrm{L}$ & $90 \pm 19$ & $111 \pm 16$ & $186 \pm 37^{*}$ \\
\hline Total CD16+ \% & $7.6 \pm 1.2$ & $3.3 \pm 0.7^{\star *}$ & $3.8 \pm 0.9^{*}$ \\
\hline total $\mathrm{CD} 16+/ \mu \mathrm{L}$ & $207 \pm 35$ & $65 \pm 12^{\star *}$ & $110 \pm 36^{*}$ \\
\hline Total CD57+ \% & $14.3 \pm 1.5$ & $24.5 \pm 2.8^{* *}$ & $22.0 \pm 3.0^{*}$ \\
\hline total CD $57+/ \mu \mathrm{L}$ & $388 \pm 50$ & $482 \pm 62$ & $601 \pm 92^{*}$ \\
\hline CD16+, CD57- \% & $3.6 \pm 0.4$ & $2.1 \pm 0.4^{*}$ & $2.0 \pm 0.5^{\star}$ \\
\hline CD16+, CD57 $-/ \mu \mathrm{L}$ & $96 \pm 12$ & $42 \pm 8^{\star *}$ & $54 \pm 14^{*}$ \\
\hline CD16+, CD57+ \% & $4.0 \pm 0.9$ & $1.3 \pm 0.3^{*}$ & $1.8 \pm 0.7$ \\
\hline CD16, CD57+ $/ \mu \mathrm{L}$ & $110 \pm 24$ & $27 \pm 5^{\star \star}$ & $51 \pm 21$ \\
\hline CD16-CD57+ \% & $10.3 \pm 1.1$ & $23.1 \pm 2.7^{\star *}$ & $20.5 \pm 0.5^{\star *}$ \\
\hline CD16-CD57+/ $/ \mu \mathrm{L}$ & $264 \pm 36$ & $457 \pm 60^{\star *}$ & $556 \pm 96^{\star \star}$ \\
\hline Total CD56+ \% & $14.3 \pm 1.8$ & $8.1 \pm 1.1^{\star *}$ & $9.9 \pm 2.1$ \\
\hline total CD56+/ $\mu \mathrm{L}$ & $380 \pm 59$ & $156 \pm 20^{\star *}$ & $279 \pm 63^{\circ}$ \\
\hline CD56+, CD3- \% & $9.3 \pm 1.4$ & $4.9 \pm 0.8^{*}$ & $6.8 \pm 1.7$ \\
\hline $\mathrm{CD} 56+, \mathrm{CD} 3-/ \mu \mathrm{L}$ & $246 \pm 42$ & $95 \pm 12^{* *}$ & $196 \pm 46^{\circ}$ \\
\hline
\end{tabular}

Data indicate mean + SEM; act. $T$ cells $=T$ activated lymphocytes, i.e. $C D 3+$ HLADR+cells. ${ }^{*}=P<0.05$ and ${ }^{* *}=P<0.01$ vs. HIV $-;{ }^{\circ}=P<0.05$ and ${ }^{\circ 0}=P<0.01$ vs. $\mathrm{HIV}+\mathrm{P}$ 
Table 2 Propensity to apoptosis of peripheral blood mononuclear cells from control seronegative subjects (HIV-), seropositive progressors $(\mathrm{HIV}+\mathrm{P})$ and long term non progressors (LTNP)

\begin{tabular}{lccc}
\hline Apoptosis & HIV - & HIV+P & LTNP \\
\hline Spontaneous & $6.3 \pm 0.8$ & $15.8 \pm 2.3^{\star \star}$ & $8.9 \pm 1.3^{\circ}$ \\
Spont.+IL-2 & $3.8 \pm 0.5^{\S}$ & $7.4 \pm 1.2^{\star \star \S \S}$ & $3.8 \pm 0.5^{\circ}$ \\
Spont.+NAM & $5.3 \pm 0.6$ & $9.9 \pm 1.7^{\star \S \S}$ & $5.8 \pm 1.2^{\S}$ \\
Spont.+NAC & $8.7 \pm 0.8$ & $15.5 \pm 2.0^{\star \star}$ & $10.3 \pm 1.2$ \\
Spont.+LAC & $7.6 \pm 1.2$ & $21.3 \pm 3.0^{\star \star}$ & $8.9 \pm 1.2^{\circ}$ \\
Spont.+3-ABA & $7.7 \pm 1.1$ & $21.5 \pm 3.6^{\star \star}$ & $10.3 \pm 1.1^{\circ}$ \\
PWM-induced & $14.2 \pm 1.0^{\S \S}$ & $23.5 \pm 2.2^{\star \star \S \S}$ & $15.1 \pm 1.5^{\circ \S}$ \\
PWM-ind.+NAC & $12.4 \pm 1.2^{\S \S}$ & $23.8 \pm 2.8^{\star \star \S \S}$ & $15.0 \pm 2.0^{\circ}$ \\
D-RIB-induced & $53.7 \pm 3.2^{\S \S}$ & $64.1 \pm 3.3^{\star \S \S}$ & $52.4 \pm 3.2^{\circ \S}$ \\
D-RIB-ind.+NAC & $9.4 \pm 1.4^{\#}$ & $15.6 \pm 1.4^{\star \star \#}$ & $10.6 \pm 0.8^{\circ}$ \\
D-RIB-ind.+IL-2 & $48.4 \pm 2.8^{\S \S}$ & $65.0 \pm 2.7^{\star \star \S \S}$ & $51.9 \pm 3.0^{\circ \diamond}$ \\
Anti-CD95-induced & $9.4 \pm 1.0$ & $20.4 \pm 3.0^{\star \S}$ & $12.0 \pm 1.4$ \\
\hline
\end{tabular}

Data indicate mean \pm SEM, and are referred to the percentage of apoptotic cells after $72 \mathrm{~h}$ of culture. Subjects are those as in Table 1, except for the study of anti-CD95-induced apoptosis, where we could analyze only four donors per group. ${ }^{*}=P<0.05$ and ${ }^{* *}=P<0.01$ vs. HIV $-;{ }^{\circ}=P<0.05$ and ${ }^{\circ 0}=P<0.01$ vs. HIV $+P$; ${ }^{\S}=P<0.05$ and ${ }^{\$ \S} P<0.01$ vs. spontaneous apoptosis; ${ }^{\#} P<0.01$ vs. D-RIBinduced apoptosis.

Table 2 reports data concerning PBMC tendency to undergo apoptosis, and the effects of various agents on this phenomenon. To investigate different possible pathways, we used a variety of apoptotic stimuli or molecules capable of inhibiting such a process. At the beginning of the culture, no differences in cell viability were observed among the subjects of the three groups. Moreover, no apoptotic cells nor cells with mitochondrial alterations were present in $\mathrm{HIV}+$ donors (data not shown). After $72 \mathrm{~h}$ of culture, spontaneous apoptosis was much higher in $\mathrm{HIV}+\mathrm{P}$ than in controls, as expected and already reported by other authors (Gougeon et al, 1993, 1996). Cells from LTNP showed a tendency to undergo apoptosis not significantly different from that of HIV - donors. In contrast with what was observed during primary, acute HIV syndrome (Cossarizza et al, 1997), adding NAC at the beginning of the culture did not modify this parameter. The presence of IL-2 provoked a marked and statistically significant $(P<0.01)$ reduction of apoptosis in all groups. NAM caused a moderate protective effect on spontaneous apoptosis, while LAC or 3-ABA were ineffective. Due to lack of cells, anti-CD95-induced apoptosis was studied in four donors per group. No main differences were found between LTNP and HIV - donors, while in HIV+P apoptosis was significantly higher than in the other two groups.

Adding $10 \mathrm{mM}$ D-RIB, an agent capable of provoking a dramatic decrease of intracellular GSH (D. Monti et al, submitted), caused a relevant increase of apoptosis in all the groups studied ( $P$ always $<0.001)$. Interestingly, such increase was of the same magnitude in all groups (about $40-42 \%$ ). In D-RIB-treated cells, adding IL-2 had no effect, while NAC consistently decreased the percentage of apoptotic cells to an extent similar to that of basal values. If cells were treated with lower doses of D-RIB ( 1 and $5 \mathrm{mM}$ ), the percentages of apoptotic cells increased over spontaneous apoptosis in a similar manner (about 8-15\%) in all the groups and, again, NAC decreased such value to those of control, untreated cultures (not shown). PWM was able to significantly increase apoptosis in all groups
( $P<0.01$ vs untreated cultures), and cells from $\mathrm{HIV}+\mathrm{P}$ showed the highest sensitivity to the mitogen.

The analysis of spontaneous apoptosis after 24, 48 and $72 \mathrm{~h}$ of culture showed that a similar kinetics was present among the three groups, even if at different absolute values of apoptosis (not shown).

Figure 1 shows that, considering all $\mathrm{HIV}+$ subjects, i.e. both HIV+P and LTNP, a significant correlation was observed when the percentage of CD4+ $T$ (negative correlation) or the percentage of T cells expressing HLADR molecules (positive correlation) were plotted against the percentage of cells undergoing spontaneous apoptosis, measured with the $\mathrm{PI}$ method. The same significant correlations were observed when these two groups were analyzed separately, or if the absolute number of circulating CD4+ or CD8+ $T$ cells were plotted (not shown).

We were interested in evaluating the modifications of lymphocyte subpopulations during the apoptotic process. For this reason, by using a cytofluorimetric technique based upon the combined evaluation of physical parameters and CD45 expression, we analyzed separately viable (Figure 2) and apoptotic (Figure 3 ) cells in the same samples. Figure 2 shows a representative experiment out of four where the
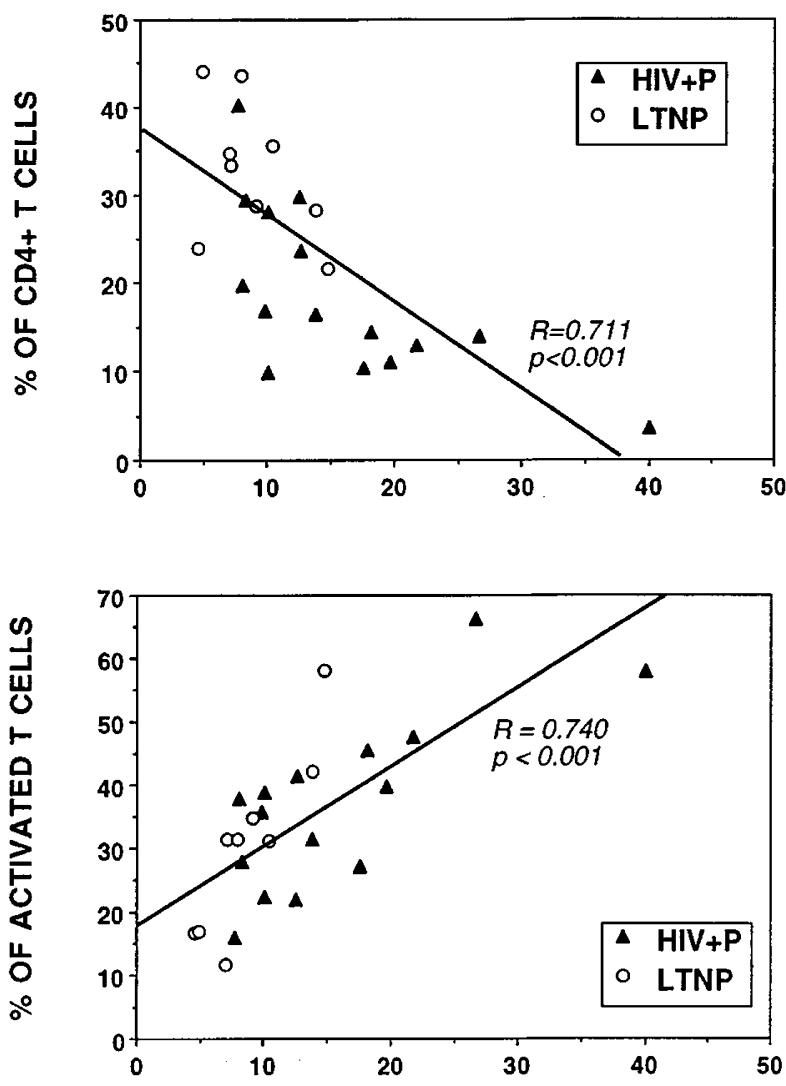

$\%$ OF SPONTANEOUS APOPTOSIS

Figure 1 Inverse correlation between the percentage of CD4+ cells and spontaneous apoptosis (measured in total PBMC by the PI method), and direct correlation between the percentage of activated $T$ cells (i.e. those expressing HLA-DR antigens) and spontaneous apoptosis in LTNP and HIV+P 
phenotypes of lymphocytes still viable at different time points were analyzed. As in the other experiments, cells were from one HIV - , one LTNP and one HIV+P. In the region of viable lymphocytes (i.e. where, in parallel samples, cells did not incorporate $\mathrm{PI}$, and maintained normal physical parameters and CD45 expression), we noted that the percentage of CD3+, CD4+ and CD8+ lymphocytes did not vary over time, while cells with NK markers (CD16, CD57) and B lymphocytes tended to increase and decrease, respectively. The pattern of these changes was similar in all the subjects of the three groups. The analysis of the phenotype of apoptotic cells, performed after $24 \mathrm{~h}$ of culture, confirmed the trend indicated by the data obtained analyzing viable cells. Figure 3 shows that, in that particular experiment, the phenotype of apoptotic cells was similar in the three donors studied, i.e. one LTNP, one $\mathrm{HIV}+\mathrm{P}$ and one HIV - control. Most apoptotic cells were CD3+ or CD4+, but also CD16+ or CD19+. Similar results were obtained in the other three experiments. For technical reasons, i.e. because of the relevant autofluorescence of apoptotic cells, it was not possible to perform such analyses at 48 or $72 \mathrm{~h}$.

Table 3 shows the intracellular GSH content in PBMC from HIV - , HIV+P and LTNP. LTNP had an intracellular GSH content which was significantly lower than that of $\mathrm{HIV}$ - and significantly higher than that of HIV+P. Linear regression analysis in all HIV+ donors, including LTNP, showed that spontaneous apoptosis was inversely correlated with intracellular GSH content (Figure 4). We could measure intracellular GSH and spontaneous apoptosis in
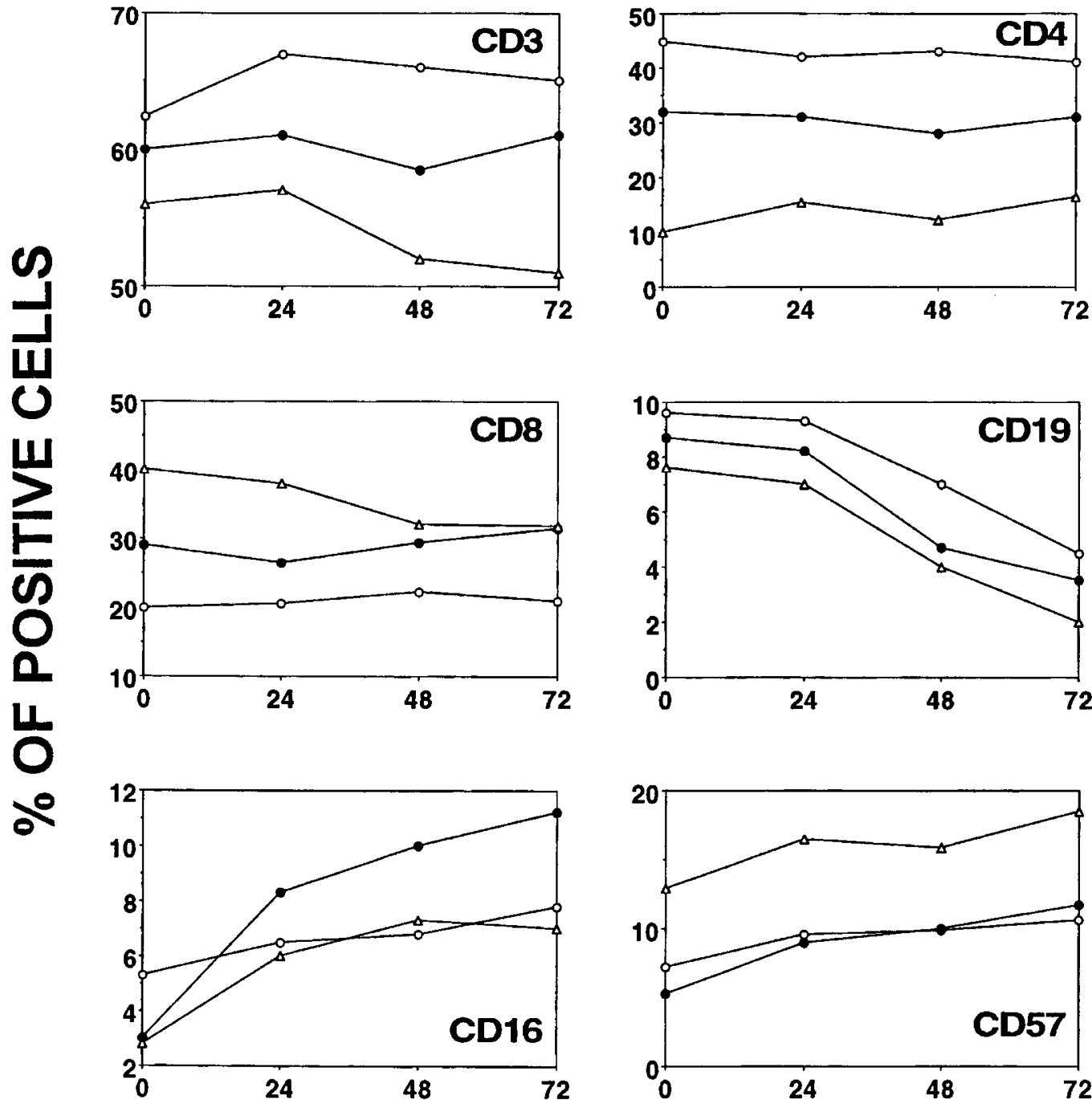

TIME (hours)

Figure 2 The phenotype of viable lymphocytes at different time points is similar in cells from one HIV - donor (open circles), one HIV+P (open triangles) and one LTNP (closed circles). Data refer to one representative experiment out of four performed on cells from one subject of each group. The phenotype of viable cells was performed by flow cytometry, using the PI exclusion method and anti-CD45 mAb. See text for details 
PBMC collected from three HIV+P donors and 4 HIV controls (not included in this paper) once a week for three times. In these samples, we could find only negligible variations of the parameters under investigations (data not shown). This indicates that the measures reported in this study are reliable and representative of each single donor.

\section{Discussion}

The scientific community is paying a growing attention to those subjects who have been infected by HIV since several years (at least seven) but in whom the infection seems unable to progress, i.e. the so-called LTNP (Levy, 1993; Baltimore, 1995a,b; Klein and Miedema, 1995). They represent a natural model for understanding the mechanisms which are able to contrast the progression of infection. Indeed, apart from the lack of clinical signs, the main inclusion criteria for being considered a LTNP is a high, or at least stable level of CD4+T cells. The available data indicate that LTNP have strong virusinhibitory CD8+ lymphocyte and neutralizing-antibodies responses, and low levels of virion replication (Cao et al, 1995; Pantaleo et al, 1995). We found that a low propensity to undergo apoptosis in PBMC can be added to the characteristics of LTNP. However, they have a complex immunological derangement, regarding in particular their phenotype and their PBMC intracellular glutathione content.

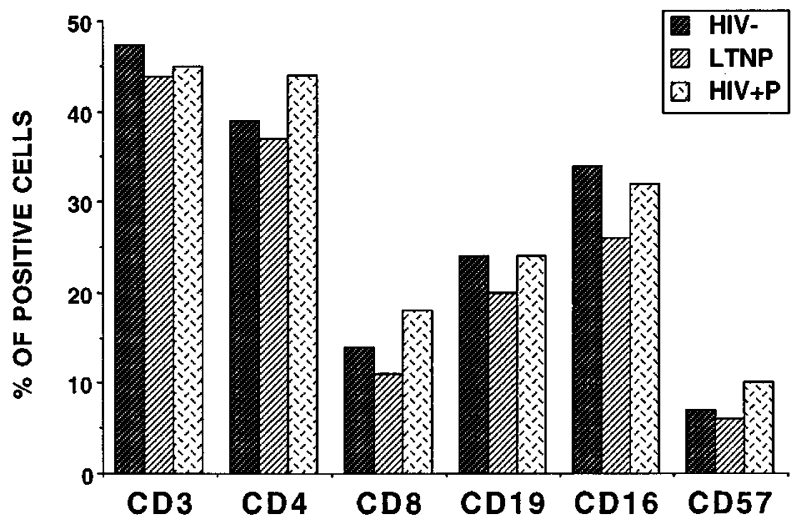

Figure 3 The phenotype of apoptotic lymphocytes after $24 \mathrm{~h}$ of culture is similar in one HIV - donor, one HIV+P and one LTNP. Data refer to one representative experiment out of four, performed on cells from one subject of each group. The phenotype of apoptotic cells was studied by flow cytometry, analyzing changes in FSC, SSC and in CD45 fluorescence. See text for details

Table 3 GSH content in peripheral blood mononuclear cells from control seronegative subjects (HIV -$)$, seropositive progressors $(\mathrm{HIV}+\mathrm{P})$ and long term non progressors (LTNP)

\begin{tabular}{lccc}
\hline & HIV - & HIV+P & LTNP \\
\hline N. of subjects & 11 & 10 & 7 \\
GSH (nmol/10 & $4.65 \pm 0.37$ & $1.70 \pm 0.20$ & $3.03 \pm 0.63$ \\
PBMC) & & & \\
\hline
\end{tabular}

Data are expressed as mean \pm SEM; statistical analysis by 2-tail Student's $t$-test: HIV - vs. HIV+: $t=6.813, P<0.001$; HIV - vs. LTNP: $t=2.379, P=0.030$; LTNP vs. $\mathrm{HIV}+:=2.322, P=0.035$
In LTNP, spontaneous, Fas-induced and mitogeninduced apoptosis of PBMC, was of the same order of that found in HIV - , and significantly lower than that of $\mathrm{HIV}+\mathrm{P}$. This phenomenon is in apparent contrast with a variety of immunological alterations regarding PBMC phenotype. Indeed, apart from the inclusion criteria, in LTNP most parameters were strikingly similar to those found in $\mathrm{HIV}+\mathrm{P}$. The main alterations were a significant expansion in CD8+ T cells, a high number and percentage of $\mathrm{T}$ cells expressing HLA-DR molecules (classical markers of activation), a decrease in cells with markers characteristic of NK subset with high cytotoxic activity (CD16+, CD57-), and an increase in CD5+ B lymphocytes, i.e. B cells that are likely involved in autoimmune phenomena (Chen and Kearney, 1996).

An apparent discrepancy exists between the low level of apoptosis and the high level of activation of LTNP's immune system. One possible explanation is that the expression of HLA-DR is not a fully reliable marker of $T$ cell activation if compared, for example, to CD38, whose expression increases in parallel with the progression of the infection and has a good prognostic value (Levacher et al, 1992; Giorgi et al, 1993). Another possibility is that, as MHC class II molecules are mainly expressed by CD8+ T lymphocytes, these cells are less prone to apoptosis in LTNP than in HIV+P. However, the fact that we found no main differences in the phenotypes of cells undergoing apoptosis among LTNP, HIV+P and HIV - does not support this explanation. In any case, further studies are needed to better identify the phenotype and clarify the role and destiny of activated T cells in LTNP.

A dynamic perspective can also be considered. According to the recent hypothesis of 'blind $T$ cell homeostasis' (Adleman and Wolsfy, 1993; Margolick et al, 1993, 1995; Roederer, 1995), the continuous erosion of CD4 compartment by apoptosis and/or other mechanisms would accel-

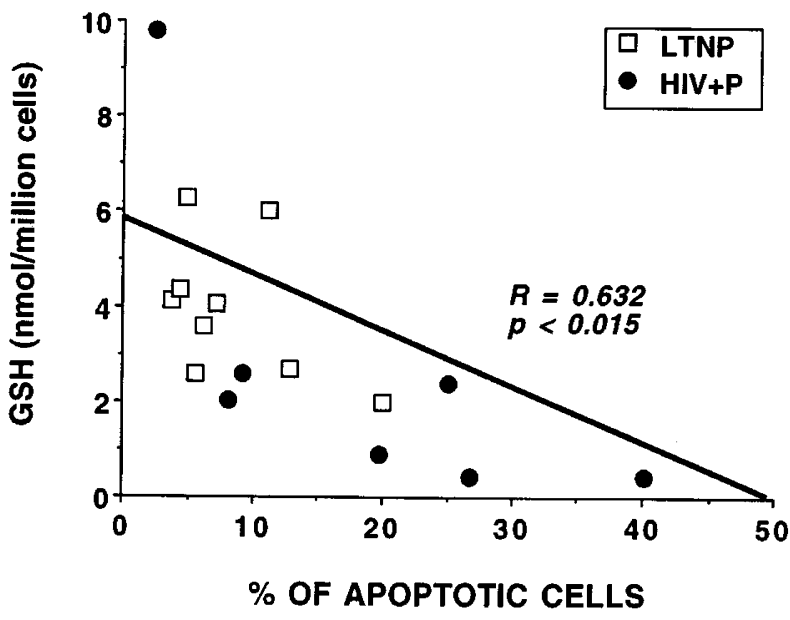

Figure 4 In LTNP and HIV+P, an inverse correlation was found between spontaneous apoptosis, measured in total PBMC after $72 \mathrm{~h}$ of culture in the absence of any stimulus by the cytofluorimetric method of the hypodiploic peak revealed by $\mathrm{PI}$, and intracellular glutathione content 
erate the normal homeostatic mechanism devoted to the maintenance of a constant level of circulating T cells, without regard to the phenotype (CD4+ or CD8+) of the T cell. One of the main consequences of this hypothesis is that it is possible to explain the concomitant decrease in CD4+ and increase in CD8+ lymphocytes along the years from seroconversion, or present in the acute primary infection (Cossarizza et al, $1995 a, b)$. Assuming that what happens in vitro is a reliable mirror of the situation existing in vivo, the scenario likely present in LTNP could be the following: a low level of apoptosis, and the consequent reduced rate of CD4+ loss, likely accompanied by a low viral burden or by the presence of a defective virus (Cao et al, 1995; Kirchhoff et al, 1995), would trigger a renewal of CD4+ and CD8+ T cells lower than that present in HIV+P. However, owing to the chronicity of the process and to the length of the period in which this phenomenon occurs, an activation of the $T$ cell compartment, and particularly an expansion of CD8+ lymphocytes, could be expected also in LTNP. In other words, the immunological consequences of HIV infection could be qualitatively similar in HIV+P and LTNP, but different from a quantitative point of view (rate of cell loss/rate of cell renewal). Accordingly, in LTNP the eventual failure of the T cell homeostasis would be significantly delayed, or even absent (Margolick et al, 1995). Independent support for this hypothesis is given by the correlations between spontaneous apoptosis and phenotype. An inverse correlation between apoptosis and the number of CD4+ cells/ $\mu \mathrm{L}$ of blood or the percentage of CD4+ cells present at the beginning of the culture, and a direct correlation between apoptosis and the percentage of HLA-DR+ T cells, were found in both $\mathrm{HIV}+\mathrm{P}$ and LTNP.

HIV-infected patients are in oxidative imbalance, which starts early in the course of the disease and they display low levels of serum and tissue antioxidants, as well as elevated concentrations of peroxidation products and clastogenic factors (Dröge et al, 1988; Eck et al, 1989; Roederer et al, 1991; Staal et al, 1992a,b; Fuchs et al, 1995). Several studies suggest that in HIV patients a significant decrease in intracellular GSH content occurs (Eck et al, 1989; Buhl et al, 1990; de Quay et al, 1992), and that this is a good prognostic marker of the infection (Herzenberg et al, 1997). It has also been demonstrated that cells with high GSH content, either CD4+ or CD8+, are selectively lost during HIV infection, even in the symptom free stages of the disease (Roederer et al, 1991; Staal et al, 1992a). Thus, also the immune system of LTNP could be under an oxidative stress, and it is reasonable to hypothesize that in LTNP the same selective loss of highGSH cells occurs. In any case, the decrease in GSH content in PBMC from LTNP likely does not reach the threshold necessary to significantly increase spontaneous cell death. The lack of an effect of NAC on spontaneous apoptosis supports this interpretation.

PBMC from LTNP were not more sensitive to D-RIB, a potent inducer of apoptosis in human lymphocytes (Barbieri et al, 1994), whose action is mediated by an early and marked decrease in intracellular GSH content (unpublished observations). NAC was able to fully prevent D-RIBinduced apoptosis, but not spontaneous apoptosis, in all groups, suggesting that cells from HIV - , HIV+P and LTNP are equally sensitive to a strong GSH depletion, notwithstanding their different basal intracellular GSH content. Thus, the effect of NAC on T cell functions cannot be simply related to the changes in GSH levels, as also observed by other authors (Kinscherf et al, 1994).

Our data offers further information on apoptosis in LTNP. First, it is interesting to note that PWM-induced apoptosis was increased in HIV+P, as expected, but not in LTNP. This would suggest that, even if it has been shown that activation-induced apoptosis equally regards CD4+ and CD8+ T cells (Katsikis et al, 1996), the T cell activation in LTNP is likely to be different from that of HIV+P.

Second, the results concerning Fas-induced apoptosis are consistent with the observations that: (i) in peripheral lymphocytes from HIV+ patients the expression of CD95 increases with the progression of the disease, and is correlated with the percentage of CD4+ T lymphocytes (Gehri et al, 1996). CD95 was found expressed in CD4+ or CD8+ T cells; (ii) activated CD8+ $\mathrm{T}$ cells present lower levels of the anti-apoptotic protein bcl-2 and, subsequently, higher levels of CD95 (Boudet et al, 1996). Low bcl-2 expressing cells were negatively correlated with the percentage of CD4+ T cells, and this is clearly consistent with the well known evidence that $T$ cell activation increases with the progression of the disease; and (iii) Fas-induced apoptosis is modulated by intracellular glutathione content (Chiba et al, 1996). Indeed, in comparison with HIV+P, PBMC from LTNP had less activation, more intracellular GSH, and were less sensitive to Fas-induced apoptosis. However, it has been shown that CD4+ cells from HIV+ subjects are more sensitive to Fasinduced apoptosis than CD8+ (Katsikis et al, 1996), and further studies are in progress to ascertain whether such phenomenon is present also in cells from LTNP. Moreover, studies on CD95L will be crucial as well to clarify the role of this pathway in LTNP.

Third, our data show that, as for subjects with primary, acute HIV infection (Cossarizza et al, 1997), several agents can be used to modulate apoptosis, even if their effects and mechanisms of action is likely quite different. In all groups, IL-2 was able to decrease spontaneous apoptosis of about $50 \%$. This confirms, and extends to LTNP, previous observation on the role of CD4+ and IL-2 production in apoptosis of HIV patients (Pandolfi et al, 1995) and gives a possible explanation for the recent report on the capability of IL-2 to increase in vivo CD4+ cells (Kovacs et al, 1995).

A similar, even if less marked effect on spontaneous apoptosis was observed with NAM, a molecule that is able to increase intracellular levels of NAD and ATP (Monti et al, 1992). NAM is able to exert its action through the inhibition of poly(ADP-ribose)polymerase (PARP), and has been shown to protect cells from death induced by oxygen free radicals, cytotoxic effector cells and tumour necrosis factor (TNF)- $\alpha$ (Agarwal et al, 1988; Marini et al, 1990; Monti et al, 1994). However, the fact that 3-ABA, a classical inhibitor of PARP, was not capable of reducing spontaneous apoptosis could indicate that the effect of NAM was likely to be PARP-independent and mediated by other structures, such as cytoskeleton (Malorni et al, 1994). 
In conclusion, a normal in vitro propensity to undergo spontaneous and induced apoptosis appears to be a major feature of PBMC from LTNP. However, many other immune parameters, such as the increase in CD8+ and activated $T$ cells, the expansion of CD5+ B cells, the decrease in 'true' NK cells, as well as some signs of oxidative stress are similar in LTNP and HIV+P, suggesting that the immune system of LTNP is quite activated, and can be modulated by several agents such as NAM and IL-2, among others. The data here reported may contribute to understanding the fact that such subjects remain asymptomatic for many years. Thus, apoptosis can be considered an important host factor which, together with other relevant virologic and imunologic characteristics (low levels of HIV-1, a combination of strong virus-specific immune responses with some degree of attenuation of the virus) (Cao et al, 1995; Pantaleo et al, 1995), can play a role in the balance between virologic factors and immune responses peculiar of LTNP. A fundamental question remains open, concerning the possible occurrence of low tendency to apoptosis in lymph-nodes or in other immune organs of LTNP.

\section{Materials and Methods}

\section{Subjects}

This study was performed with the informed consent of the donors. Peripheral blood samples were obtained from 42 subjects ( 19 females and 23 males) living in San Patrignano Community (Rimini, Italy) - the biggest Italian community for former drug addicts. They have been selected among more than $500 \mathrm{HIV}$ + subjects or 1500 seronegative persons who are living in optimal and controlled environmental condition (adequate nutrition, lack of drug assumption or alcohol, etc.), and are continuously followed and monitored from both a clinical and laboratory point of view. They represent a unique homogeneous consistent population of HIV+ people, which we are studying for many years.

Donors were subdivided in three groups with approximately the same number of males and females. The first group was formed by 15 $\mathrm{HIV}+\mathrm{P}$, defined as those patients losing more than $150 \mathrm{CD} 4+\mathrm{cells} / \mu \mathrm{L} /$ year in the last 5 years; the second by 9 LTNP, i.e. subjects infected by HIV for at least 7 years, but who do not present clinical or immunological signs of progression of the infection, and with a stable number of CD4+ cells in the last years, as described elsewhere (Klein and Miedema, 1995; Pantaleo et al, 1995). All LTNP had >640 CD4+ cells $/ \mu \mathrm{L}$ (range: $640-1209$ ). In these subjects, in the last year the modification of circulating CD4+ lymphocytes was $+50.2 \pm 34.6$ cells / $\mu \mathrm{L}$ (range: $-92,+153$ ). The third group was formed by 18 seronegative controls (HIV -) with a history of drug abuse over the past years similar to that of HIV+ subjects. Blood samples were taken between 7:00 and 9.00 a.m., coded, immediately brought to Modena and processed in a single-blind manner, so that the operators did not know if a given sample was from a HIV - , a HIV+P or a LTNP. A minimum of three blood samples (one HIV - , one HIV+ and one LTNP) were studied in each experiment.

All donors were tested for several bacterial and viral pathogens, and serological evaluation for hepatitis B virus, Epstein-Barr virus, cytomegalovirus, Chlamidia, Mycoplasma and Toxoplasma infection were all negative. Syphilis serologic findings were non-reactive. No subject had herpesvirus infections.

\section{Chemicals and monoclonal antibodies}

NAC (final concentration: $10 \mathrm{mM}), \mathrm{D}-\mathrm{RIB}(1-10 \mathrm{mM})$, NAM (5 mM), 3ABA $(5 \mathrm{mM})$, PWM $(2.5 \mu \mathrm{g} / \mathrm{mL})$ and propidium iodide (PI) were purchased from Sigma Chem. (St. Louis, MO, USA); human recombinant IL-2 $(20 \mathrm{U} / \mathrm{mL})$ from Boehringer (Mannheim, Germany). LAC ( $5 \mathrm{mM}$ ) was kindly provided by Sigma Tau SpA, Pomezia, Roma, Italy.

We used the following commercially available monoclonal antibodies (mAb), purchased from Becton Dickinson (San José, CA, USA), or Sigma Chem., directly conjugated with fluorescein, phycoerythryn or quantum red: anti-CD3, anti-CD4, anti-CD5, antiCD8, anti-CD16, anti-CD19, anti-CD45, anti-CD56, anti-CD57, antiHLA-DR. Anti-CD95 (clone APO1-3) was from Bender (Vienna, Austria), and goat-anti-mouse antibodies from Dako (Glostrup, Denmark).

\section{Blood collections and PBMC cultures}

PBMC were separated by discontinuous density gradient centrifugation, following standard methods. In all cases, the percentage of granulocytes after the separation was negligible $(<1 \%)$. Cultures were then prepared by placing $1 \times 10^{6}$ cells $/ \mathrm{mL}$ in 24 well plates (Costar, Cambridge, MA, USA), in complete culture medium, i,e., RPMI-1640 medium (Flow Laboratories, Rockville, MD, USA) supplemented with $10 \%$ heat-inactivated $\left(56^{\circ} \mathrm{C}\right.$ for $\left.30 \mathrm{~min}\right)$ fetal bovine serum (FBS; Gibco Laboratories, Grand Island, NY, USA), 2 mM glutamine, 100 $\mathrm{U} / \mathrm{mL}$ penicillin, and $100 \mu \mathrm{g} / \mathrm{mL}$ streptomycin. In each well, we also added one or a combination of the above mentioned chemicals, reaching a total volume of $2 \mathrm{~mL}$. PBMC were then incubated for different times (up to $72 \mathrm{~h}$ ) in humidified $5 \% \mathrm{CO}_{2}$ and $95 \%$ air at $37^{\circ} \mathrm{C}$. At the end of incubation periods, cells were collected, washed twice with cold phosphate buffered saline (PBS), and prepared for flow cytometric analysis. For the analysis of Fas-induced apoptosis, PBMC were incubated for $1 \mathrm{~h}$ at $4^{\circ} \mathrm{C}$ with $0.1 \mu \mathrm{g} / \mathrm{mL}$ anti-CD95 $\mathrm{mAb}$, washed, incubated for $30 \mathrm{~min}$ at $4^{\circ} \mathrm{C}$ with the secondary $\mathrm{mAb}$, washed and cultured for $24 \mathrm{~h}$.

\section{Detection of apoptosis}

Apoptosis was detected in individual cells by reduced fluorescence of the PI-a DNA binding dye-in the apoptotic nuclei, according to Nicoletti et al. (Nicoletti et al, 1991). Briefly, cells were collected and washed, and the $200 \mathrm{~g}$ centrifuged cell pellet was gently resuspended in $1 \mathrm{~mL}$ hypotonic fluorochrome solution (PI $50 \mu \mathrm{g} / \mathrm{mL}$ in $0.1 \%$ sodium citrate plus $0.1 \%$ Triton X-100, Sigma). Cells were analyzed after a miminum of 30 min of incubation in the dark at room temperature in this solution.

\section{Cell viability}

Cell viability was cytofluorimetrically analyzed by the method of $\mathrm{PI}$ exclusion (Cook and Mitchel, 1989). Samples were incubated with $10 \mu \mathrm{g} / \mathrm{mL}$ PI for $5 \mathrm{~min}$ at room temperature in the dark and immediately analyzed.

\section{Phenotype analysis and immunofluorescence staining}

Phenotypic analyses of lymphocyte subpopulations were performed on the same blood samples collected for the study of PMBC tendency to undergo apoptosis. PBMC were obtained by density gradient centrifugation following standard methods, and cells were then used 
immediately for dual and triple colour cytofluorimetric analysis, performed on a FACScan (Becton Dickinson), as described previously (Cossarizza et al, 1991). Viable lymphocytes, i.e. those capable of excluding PI in parallel samples, were electronically gated on the basis of their physical parameters (FSC and SSC), and a minimum of 10000 cells per sample was acquired in list mode and analyzed by Lysys II software program.

As far as the study of the modifications of lymphocyte phenotype during spontaneous apoptosis are concerned, we used the following approach. Cells were cultured, collected at different time points, and stained with different mAbs. Then, first, viable lymphocytes were electronically gated taking into account their physical parameters. The analysis of parallel samples revealed that these cells had a normal CD45 membrane expression and were capable to exclude PI. A minimum of 10000 cells were acquired and analyzed. Second, an electronic gate was set in the physical region of apoptotic cells, i.e. those with lower forward and higher side angle scatter, and with reduced CD45 membrane expression, as previously reported (Carbonari et al, 1994). In this case, a minimum of 5000 cells per sample were acquired in list mode and analyzed as described above. Due to shortage of cells, we could investigate four subjects in each group. Four experiments were thus performed, in which cells from one donor per group were studied.

\section{Intracellular reduced glutathione content}

The measure of PBMC intracellular GSH content was performed according to the method proposed by Reed et al, (1980). Due to shortage of cells, we could analyze 7 LTNP, $10 \mathrm{HIV}+\mathrm{P}$ and 11 controls. Briefly, $10^{6}$ PBMC were resuspended in a $0.9 \mathrm{~mL}$ of $10 \%$ trichloroacetic acid water solution to remove protein and centrifuged at $5000 \mathrm{rpm}$ for $5 \mathrm{~min}$. The supernatant was treated immediately with $50 \mu \mathrm{l}$ of a fresh iodoacetic acid aqueous solution $(4 \mu \mathrm{M})$, and then the obtained mixture was neutralised with an excess of $\mathrm{NaHCO}_{3}$ dry powder to form S-carboxymethyl derivatives. After $60 \mathrm{~min}$ in the dark at room temperature, $0.1 \mathrm{~mL}$ of analcoholic solution of 1-fluoro 2,4-dinitrobenzene was added. The provoked reaction was allowed to proceed for $24 \mathrm{~h}$ in the dark, and this led to the formation of N-DNP derivatives that were resolved by high performance liquid chromatography (HPLC) analysis. The samples were stored at $-20^{\circ} \mathrm{C}$ until analysis by HPLC. A Beckman Gold HPLC equipped with a Waters Bondapak amine column was used to resolve DNP derivatives. Solvent A was 4:1 methanol:water (v/v) and solvent B was prepared as follows: $272 \mathrm{~mL}$ sodium acetate trihydrate, $122 \mathrm{~mL}$ water and $378 \mathrm{~mL}$ glacial acetic acid were mixed and $200 \mathrm{~mL}$ of the resulting solution was added to $800 \mathrm{~mL}$ of solvent $A$. An isocratic period of $10 \mathrm{~min}$ at $25 \%$ of $B$ was followed by a programmed linear gradient from $25-95 \%$ solvent B over a $20 \mathrm{~min}$ period. An aliquot of $40 \mu \mathrm{L}$ of the sample was usually injected in the column using an autosampler Beckman mod. 507, and GSH was determined at $365 \mathrm{~nm}$.

\section{Statistical analysis}

Statistical analysis was performed by two tails paired or unpaired Student's $t$-test and by linear regression analysis, using SPSS ${ }^{\circledR}$ for Windows software. A $P$ value lower than 0.05 was considered significant.

\section{Acknowledgements}

This work has been supported by Istituto Superiore di Sanità, Rome (Italy): IX Progetto di Ricerche sull'AIDS, grant \# 9402-09.

\section{References}

Adleman LM and Wolsfy D (1993) T-cell homeostasis: implications in HIV infection. J. Acquir. Immune Defic. Syndr. Hum. Retrovirol. 6: 144-152

Agarwal S, Drysdale BE and Shin HS (1988) Tumor necrosis factor-mediated cytotoxicity involves ADP-ribosylation. J. Immunol. 140: 4187-4192

Ameisen JC and Capron A (1991) Cell dysfunction and depletion in AIDS: the programmed cell death hypothesis. Immunol. Today 4: 102-105

Ameisen JC, EstaquierJ, Idziorek T and De Bels F (1995) Programmed cell death and AIDS: significance, perspectives and unanswered questions. Cell Death Differ. 2: $9-22$

Baltimore D (1995a) The enigma of HIV infection. Cell 82: 175-178

Baltimore D (1995b) Lessons from people with nonprogressive HIV infection. N. Engl. J. Med. 332: 259-260

Barbieri D, Grassilli E, Monti D, Salvioli S, Franceschini MG, Franchini A, Bellesia E, Salomoni P, Negro P, Capri M, Troiano L, Cossarizza A and Franceschi C (1994) $D$-ribose and deoxy-D-ribose induce apoptosis in human quiescent peripheral blood mononuclear cells. Biochem. Biophys. Res. Commun. 201: 1109-1116

Boudet F, Lecoeur H and Gougeon M-L (1996) Apoptosis associated with ex vivo down-regulation of $\mathrm{Bcl}-2$ and up-regulation of Fas in potential cytotoxic $\mathrm{CD} 8+\mathrm{T}$ lymphocytes during HIV infection. J. Immunol. 156: 2282-2293

Buhl R, Jaffe AH, Holroyd KJ, Wells FB, Mastrangeli A, Saltini C, Cantin AM and Crystal RG (1990) Systemic glutathione deficiency in symptom-free HIV-positive individuals. Lancet 2: 1294-1298

Cao Y, Qin L, Zhang L, Safrit J and Ho DD (1995) Virologic and immunologic characterization of long-term survivors of human immunodeficiency virus type 1 infection. N. Engl. J. Med. 332: 202-208

Carbonari M, Cibati M, Cherchi M, Sbarigia D, Pesce AM, Dell'Anna L, Modica A, and Fiorilli M (1994) Detection and characterization of apoptotic peripheral blood lymphocytes in HIV infection and cancer chemotherapy by a novel immunocytometric method. Blood 83: 1268-1277

Chen X and Kearney JF (1996) Generation and function of natural self-reactive B cells. Sem. Immunol. 8: 19-27

Chiba T, Takahashi S, Sato N, Ishii S and Kikuchi K(1996) Fas-mediated apoptosis is modulated by intracellular glutathione in human T cells. Eur. J. Immunol. 26: $1164-1169$

Cook A and Mitchel JB (1989) Viability measurements in mammalian cell systems. Anal. Biochem. 179: 1-7

Cossarizza A, Mussini C, Mongiardo N, Borghi V, Sabbatini A, De Rienzo B and Franceschi C (1997) Mitochondria alterations and dramatic tendency to apoptosis in peripheral blood lymphocytes during acute HIV syndrome. AIDS 11: $19-26$

Cossarizza A, Ortolani C, Forti E, Montagnani G, Paganelli R, Zannotti M, Marini M, Monti D and Franceschi C (1991) Age-related expansion of functionally inefficient cells with markers of NKactivity in Down's syndrome. Blood 77: 12631270.

Cossarizza A, Ortolani C, Mussini C, Borghi V, Guaraldi G, Mongiardo N, Bellesia E, Franceschini MG, De Rienzo B and Franceschi C (1995a) Massive activation of immune cells with an intact T cell repertoire in acute HIV syndrome. J. Infect. Dis. 172: $105-112$

Cossarizza A, Ortolani C, Mussini C, Guaraldi G, Mongiardo N, Borghi V, Barbieri D, Bellesia E, Franceschini MG, De Rienzo B and Franceschi C (1995b) Lack of selective $\mathrm{V} \beta$ deletion in $\mathrm{CD} 4+$ or $\mathrm{CD} 8+\mathrm{T}$ lymphocytes and functional integrity of $\mathrm{T}$ cell repertoire during acute HIV syndrome. AIDS 9: 547-554

de Quay B, Malinverni R and Lauterburg BH (1992) Glutathione depletion in HIVinfected patients: role of cysteine deficiency and effects of oral $\mathrm{N}$-acetylcysteine. AIDS 6: 815-819

Dröge W, Eck H-P, Näher H, Peckar U and Daniel V (1988) Abnormal amino acid concentrations in the blood of patients with acquired immunodeficiency syndrome (AIDS) may contribute to the immunological defect. Biol. Chem. Hoppe-Seyler 369: 143-148

Dröge W, Schulze-Osthoff K, Mihm S, Galter D, Schenk H, Eck H-P, Roth S and Gmünder H (1994) Functions of glutathione and glutathione disulfide in immunology and immunopathology. FASEB J. 8: 1131-1138

Eck H-P, Gmünder H, Hartmann M, Petzoldt D, Daniel V and Dröge W (1989) Low concentration of soluble thiol (cysteine) in the blood plasma of HIV-1 infected patients. Biol. Chem. Hoppe-Seyler 370: 101-108 
EckH-P, Mertens T, Rosokat H, Fätkenheuer G, Pohl C, Schrappe M, DanielV, Näher H, Petzoldt D, Drings P and Dröge W (1992) T4+ cell numbers are correlated with plasma glutathione and cysteine levels: association of hyperglutamataemia with immunodeficiency in diseases with different aetiologies. Int. Immunol. 4: 12941298

Eck H-P, Stahl-Henning C, Hunsmann G and Dröge W (1991) Metabolic disorder as early consequence of simian immunodeficiency virus infection in rhesus macaques. Lancet 338: 909-912

Finkel TH and Banda NK (1994) Indirect mechanisms of HIV pathogenesis: how does HIV kill T cells? Curr. Opin. Immunol. 6: 605-615

Fuchs J, Emerit I, Levy A, Cernajvski L, Schöfer H and Milbradt R (1995) Clastogenic factors in plasma of HIV-1 infected patients. Free Rad. Biol. Med. 19: 843-848

Gehri R, Hanh S, Rothen M, Steuerwald M, Neusch R and Erb P (1996) The Fas receptor in HIV infection: expression on peripheral blood lymphocytes and role in the depletion of T cells. AIDS 10: $9-16$

Giorgi JV, Liu Z, Hultin LE, Cumberland WG, Hennessey K and Detels R (1993) Elevated levels of CD38+ CD8+ T cells in HIV infection add to the prognostic value of low CD4+ T cell levels: results of 6 years of follow-up. The Los Angeles Center, Multicenter AIDS Cohort Study. J. AIDS 6: 904-912

Gougeon ML (1995) Does apoptosis contribute to CD4 T cell depletion in human immunodeficiency virus infection? Cell Death Differ. 2: 1-8

Gougeon M-L, Garcia S, Heeney J, Tschopp R, Lecoeur H, Guétard D, Rame V, Dauguet $C$ and Montagnier L (1993) Programmed cell death in AIDS-related HIV and SIV infections. AIDS Res. Hum. Retroviruses 9: 553-563

Gougeon M-L, Lecoeur H, Dulioust A, Enouf M-G, Crouvoisier M, Goujard C, Debord $T$ and Montagnier $L$ (1996) Programmed cell death in peripheral lymphocytes from HIV-infected persons. Increased susceptibility to apoptosis of CD4 and CD8 $\mathrm{T}$ cells correlates with lymphocyte activation and with disease progession. $\mathrm{J}$. Immunol. 156: 3509-3520

Groux H, Torpier G, Monté D, Mouton Y, Capron A and Ameisen JC (1992) Activationinduced death by apoptosis in $\mathrm{CD} 4+\mathrm{T}$ cells from human immunodeficiency virusinfected asymptomatic individuals. J. Exp. Med. 175: $331-340$

Herzenberg LA, De Rosa SC, Dubs JG, Roederer M, Anderson MT, Ela SW, Deresinski SC and Herzenberg LA (1997) Glutathione deficiency is associated with impaired survival in HIV disease. Proc. Natl. Acad. Sci. USA 94: 1967-1972

Katsikis PD, Garcia Ojeda ME, Wunderlich ES, Smith CA, Yagita H, Okumura K, Kayagaki N, Alderson M, Herzenberg LA and Herzenberg LA (1996) Activationinduced peripheral blood T cell apoptosis is Fas independent in HIV-infected individuals. Int. Immunol. 8: 1311-1317

Kinscherf R, Fishbach T, Mihm S, Roth S, Hohenhaus-Sievert E, Weiss C, Edler L, Bärtsch $P$ and Dröge W (1994) Effect of glutathione depletion and oral $\mathrm{N}$-acetylcysteine treatment of $\mathrm{CD} 4^{+}$and $\mathrm{CD} 8^{+}$cells. FASEB J. 8: 448-451

Kirchhoff F, Greenough TC, Brettler DB,Sullivan JL and Desrosiers RC (1995) Brief report: absence of intact nef sequences in a long-term survivor with nonprogressive HIV infection. N. Engl. J. Med. 332: 228-232

Klein MR and Miedema F (1995) Long-term survivors of HIV-1 infection. Trends Microbiol. 3: 386-391

Kovacs JA, Baseler M, Dewar RJ, Vogel S, Davey RTJ, Falloon J, Polis MA, Walker RE, Stevens R, Salzman NP, MetcalfJA, Masur H and Lane HC (1995) Increases in CD4 T lymphocytes with intermittent courses of interleukin-2 in patients with human immunodeficiency virus infection. A preliminary study. N. Engl. J. Med. 332: $567-575$

Lanier LL and Loken MR (1984) Human lymphocyte subpopulations identified by using three color immunofluorescence and flow cytometry analysis: correlation of Leu-2, Leu-3, Leu-7, Leu-8 and Leu-11 cell surface antigen expression. J. Immunol. 132: 151-156

Laurent-Crawford AG, Krust B and Muller S (1991) The cytopatic effect of HIV is associated with apoptosis. Virology 185: 829-839

Levacher M, Hulstaert F, Tallet S, Ullery S, Pocidalo JJ and Bach BA (1992) The significance of activation markers on CD8 lymphocytes in human immunodeficiency syndrome: staging and prognostic value. Clin. Exp. Immunol. 90: 376382

Levy J (1993) HIV pathogenesis and long-term survival. AIDS 7: 1401-1410
Li CH, Friedman DJ, Wang C, Metelev V and Pardee AB (1995) Induction of apoptosis in uninfected lymphocytes by HIV-1 rat protein. Science 268: 429-431

Malorni W, Rainaldi G, Straface E, Rivabene R, Cossarizza A, Capri M, Monti D and Franceschi C (1994) 3-aminobenzamide induces cytoskeleton rearrangement in M14 melanoma cells. Biochem. Biophys. Res. Commun. 202: 915-922

Margolick JB, Donnenberg AD, Muñoz A, Park LP, Bauer KD, Giorgi JV, Ferbas J and Saah AJ (1993) Changes in T and non-T lymphocyte subsets following seroconversion to $\mathrm{HIV}-1$ : stable $\mathrm{CD}^{+}$and declining $\mathrm{CD}^{-}{ }^{-}$populations suggest regulatory responses linked to loss of CD4 lymphocytes. J. Acquir. Immune Defic. Syndr. Hum. Retrovirol. 6: 153-161

Margolick JB, Muñoz A, Donnenberg AD, Park LP, Galai N, Giorgi JV, O'Gorman MRG and Ferbas J (1995) Failure of T cell homeostasis preceding AIDS in HIV-1 infection. Nature Med. 1: 674-680

Marini M, Zunica G, Tamba M, Cossarizza A, Monti D and Franceschi C (1990) Recovery of human lymphocytes damaged with $\gamma$-radiations or enzymatically produced oxygen radicals: different effects of poly(ADP-ribosyl)polymerase inhibitors. Int. J. Radiat. Biol. 58: 279-291

Monti D, Cossarizza A, Salvioli S, Franceschi C, Rainaldi G, Straface E, Rivabene R and Malorni W (1994) Cell death protection by 3-aminobenzamide and other poly(ADP-ribose) polymerase inhibitors: different effects on human natural killer and lymphokine activated killer cell activities. Biochem. Biophys. Res. Commun. 199: $525-530$

Monti D, Troiano L, Tropea F, Grassilli E, Cossarizza A, Barozzi D, Pelloni MC, Tamassia MG and Franceschi C (1992) Apoptosis - Programmed cell death: a role in the aging process? Am. J. Clin. Nutr. 55: 1208s-1214s

Nicoletti I, Migliorati MC, Grignani F and Riccardi C (1991) A rapid simple method for measuring thymocyte apoptosis by propidium iodide staining and flow cytometry. J. Immunol. Methods 139: 271-279

Pandolfi F, Pierdominici M, Oliva A, D'Offizi G, Mezzaroma I, Mollicone B, Giovannetti A, Rainaldi L, Quinti I and Aiuti F (1995) Apoptosis-related mortality in vitro of mononuclear cells from patients with HIV infection correlates with disease severity and progression. J. Acquir. Immune Defic. Syndr. Hum. Retrovirol. 9: $450-458$

Pantaleo G and Fauci AS (1995a) Apoptosis in HIV infection. Nature Med. 1: 118 120

Pantaleo G and Fauci AS (1995b) New concepts in the immunopathogenesis of HIV infection. Annu. Rev. Immunol. 13: 487-512

Pantaleo G, Menzo S, Vaccarezza M, Graziosi C, Cohen OJ, DemarestJF, Montefiori D, Orenstein JM, Fox C, Schrager LK, Margolick JB, Buchbinder S, Giorgi JV and Fauci AS (1995) Studies in subjects with long-term nonprogressive human immunodeficiency virus infection. N. Engl. J. Med. 332: 209-216

Reed DJ, Babson JR, Beatty PW, Brodie AE, Ellis WW and Potter DW (1980) High performance liquid chromatography analysis of nanomole levels of glutathione, glutathione disulfide, and related thiols and disulfide. Anal. Biochem. 106: 55-

Roederer M (1995) T-cell dynamics of immunodeficiency. Nature Med. 1: 621-622

Roederer M, Staal FJT, Osada H, Herzenberg LA and Herzenberg LA (1991) CD4 and CD8T cells with high intracellularglutathione levels are selectively lost as the HIV infection progresses. Int. Immunol. 3: 933-937

Sheppard HW, Lang W, Ascher MS, Vittinghoff E and Winkelstein W (1993) The characterization of non-progressors: long term HIV-1 infection with stable CD4+ T-cell levels. AIDS 7: 1159-1166

Staal FJT, Ela SW, Roederer M, Anderson MT, Herzenberg LA and Herzenberg LA (1992a) Glutathione deficiency and human immunodeficiency virus infection. Lancet 339: 909-912

Staal FJT, Roederer M, Israelski DM, Bubp J, Mole HJ, McShane D, Deresinski SC Ross W, Sussman H, Raju PA, Anderson MT, Moore W, Ela SW, Herzenberg LA and Herzenberg LA (1992b) Intracellular glutathione levels in T cell subsets decrease in HIV infected individuals. AIDS Res. Hum. Retroviruses 8: 305-311

Terai C, Kornbluth RS, Pauza CD, Richman DD and Carson DA (1991) Apoptosis as a mechanism of cell death in cultured Tlymphoblasts acutely infected with HIV-1. J. Clin. Invest. 87: 1710-1715 